\title{
Are Groote Schuur Hospital anaesthesiologists burnt out? A cross-sectional study of prevalence and risk
}

\author{
MB Groenewald, (D) J van Nugteren, (D) R Parker (D) \\ Department of Anaesthesia and Perioperative Medicine, Faculty of Health, University of Cape Town, South Africa \\ Corresponding author, email: embegroenewald@gmail.com
}

Background: Burnout and physician wellness are becoming increasingly topical. While some surveys have been performed with South African anaesthesiologists, these have been conducted in limited samples. While burnout is often measured, there is a paucity of research on contributory risk and protective factors.

Method: A contextual, prospective, cross-sectional study was conducted. The Maslach Burnout Inventory-Human Services Survey (MBI-HSS) and the Areas of Worklife Survey (AWS) were used to assess burnout and contributory organisational risk factors amongst state-employed anaesthesiologists working at Groote Schuur Hospital.

Results: Out of a possible 127 members of staff (medical officers, registrars and consultants), 81 responded with 75 completing the full survey (59\% response rate). Only $4 \%$ of respondents were classified as "burnt out", defined as scoring high in all three domains of burnout: high emotional exhaustion and depersonalisation and low personal accomplishment. However, $67 \%$ of respondents scored high for at least one of the components of burnout, indicating the majority of the respondents are at risk for developing clinically significant burnout. The AWS showed that respondents found their workload inappropriate. However, responses for the categories of control, reward, community, fairness and values were all in the acceptable range.

Conclusion: While the overall rate of burnout was low, the majority of respondents were at risk for developing burnout. High perceived workload appeared to be a particular contributory factor. Protection against burnout in this group may be provided by a combination of few organisational risk factors together with feelings of personal accomplishment.

Keywords: burnout, anaesthesiologists, emotional exhaustion, depersonalisation, personal accomplishment

\section{Introduction}

Anaesthetists in South Africa are faced with ever-increasing workloads, whilst limited human and financial resources generate unprecedented levels of stress both in and out of the workplace. ${ }^{1,2}$ In the Western Cape of South Africa, trauma is common, often resulting in severe, life-threatening injuries requiring surgery. Anaesthesiology trainees managing these patients are often faced with prolonged periods of critical decision making, physical exhaustion and emotional trauma in under-resourced hospitals at night and after hours. ' Work-life balance, an essential component of managing stress, is further negatively impacted by academic responsibilities such as exam preparation and MMed requirements. ${ }^{3,4}$ Sustained stress in people without adequate coping strategies may lead to burnout syndrome. ${ }^{5}$

Burnout syndrome is characterised by exhaustion, depersonalisation and a lack of personal accomplishment. It is important to note that these three basic dimensions are concepts with broader application. Exhaustion can be described as "worn out, loss of energy, depletion, debilitation and fatigue"; depersonalisation as "cynicism, detachment from work, negative or inappropriate attitudes, irritability, withdrawal"; and personal accomplishment as "inefficacy, reduced productivity or capability, low morale and inability to cope". 6 The pathogenesis of burnout is complex and ill-defined and varies across professions. However, across professions, it involves the interplay between the work environment and its demands, together with personal, social and biological resources. ${ }^{7}$

There are multiple negative consequences of burnout on both personal and comprehensive levels. Burnout has a detrimental effect on physical health, ${ }^{8-12}$ and adverse psychological consequences with reduced job satisfaction, increased broken relationships, substance abuse and suicide. ${ }^{13}$ Burnout influences quality of care, increases the risk for medical errors and litigation and erodes professionalism. Patient's perceived quality of care is less in units where high levels of burnout exist amongst staff. ${ }^{14}$ Finally, burnout may contribute to early retirement and loss of expertise which is especially important in resource-poor environments. ${ }^{15}$

The three interrelated dimensions of burnout lead to several patterns within or on the scale between burnout and engagement and brings a clearer understanding of the work experience. ${ }^{6}$

Engaged: Low scores in emotional exhaustion and depersonalisation and high score in personal accomplishment.

Overextended: High score in emotional exhaustion only.

Disengaged: High score in depersonalisation only.

Ineffective: Low score in personal accomplishment only.

Burnout: High scores in emotional exhaustion and depersonalisation and low score in personal accomplishment.

Figure 1: Five patterns of burnout (Leitner and Maslach, 2016) 
Latent profile analysis by Leitner and Maslach has identified five distinct patterns on the burnout continuum which might point more clearly to the causative factors leading to work burnout or engagement (Figure 1). ${ }^{6}$

Studies in various South African medical professionals describe burnout rates ranging from 8-31\%. A 2013 study among Advanced Life Support Paramedics in Johannesburg showed a burnout rate of 30\%, whereas a 2017 study among rural doctors in the Western Cape showed high burnout in $31 \%$ of participants. ${ }^{16,17}$ A 2015 study at the University of the Witwatersrand found an overall burnout rate of $21 \%$ amongst public service anaesthetists but only $8 \%$ among private sector anaesthetists. ${ }^{18}$

The clinical practice of anaesthesiology is associated with inherent difficulties and stressors which cannot necessarily be modified. ${ }^{19,20}$ Healthy coping strategies and adequate social support remain the most important personal factors in buffering work-related chronic stress and strain and thus promoting resilience and reducing burnout. ${ }^{21}$ However, organisational factors of the work environment which can be modified to reduce stress have been identified. Six organisational risk factors have been identified in the work environment which, depending on how the person experiences these may lead to engagement or burnout (Figure 2).

The work experience is not a black and white construct of being burnt-out or not, but a dynamic model ranging from being fully engaged to burnout. Organisations can identify the relative roles organisational risk factors play in burnout, and thus take specific steps to address and improve the work environment, engagement with work and ultimately decrease levels of burnout. $^{23}$

Given the paucity of studies on the rates of burnout in South African medical professionals, the wide range of burnout reported, and the need to identify modifiable organisational risk factors which can be addressed to reduce the risk of burnout, we

Workload: The amount of work to be done in a given time. Control: The opportunity to make choices and decisions, to solve problems, and to contribute to the fulfilment of responsibilities.

Reward: Recognition (financial or social) you receive for your contribution at work.

Community: The quality of the social context in which you work.

Fairness: The extent to which the organisation has consistent and equitable rules for everyone, or the quality of justice and respect at work.

Values: That which matters to you at work.

Figure 2: Organisational risk factors contributing to or buffering burnout $^{22}$ aimed to assess levels of burnout and contributory organisational risk factors amongst state-employed anaesthesiologists working at Groote Schuur Hospital.

\section{Method}

A contextual, prospective, cross-sectional study was conducted. The Maslach Burnout Inventory-Human Services Survey (MBIHSS) was used in combination with the Areas of Worklife Survey (AWS), both on a copyrighted Online Platform Mindgarden. The data were scored and interpreted according to standard methods using these tools developed by Leitner and Maslach. ${ }^{6}$

\section{Sample}

All 127 state-employed doctors practising anaesthesiology at Groote Schuur Hospital Complex were sent a personalised email invitation to complete the MBI-HSS and AWS on the online platform. All doctors were registered with the Health Professions Council of South Africa as independent medical practitioners or medical specialists at the time of enrolment. Doctors were either medical officers, registrars at varied levels of completing specialist training, or medical specialists. Doctors who declined to participate in the study were excluded. No other exclusion criteria were applied.

Prior to completing the online survey, participants were required to complete informed consent. Subsequently, monthly followup emails to invite participation were sent to non-responders for a period of five months.

\section{Measurement instruments}

\section{Maslach Burnout Inventory-Human Services Survey}

The MBI-HSS 25 is a 22-item survey designed to assess the three components of burnout: emotional exhaustion (EE) - nine items; depersonalisation (DP) - five items; and lack of personal accomplishment (PA) - eight items. The sum of the component scores of the three constructs of burnout is determined numerically and graded as either high, moderate or low (Table I).

\section{Burnout profiles}

Five burnout profiles have been identified on the burnout continuum correlating with the different work experiences of employees. Two profiles score consistently across all three burnout scales and these are burnout and engaged, three one-dimension profiles are identified for inconsistent scores: ineffective, overextended and disengaged (Table II).

An engaged individual will have a positive work experience scoring low on exhaustion and depersonalisation and high on personal accomplishment. Burnout is realised when there are

Table I: Classification of components of burnout

\begin{tabular}{lccc}
\hline & High & Moderate & Low \\
\hline Emotional exhaustion & $\geq 27$ & $26-19$ & $\leq 18$ \\
Depersonalisation & $\geq 10$ & $9-6$ & $\leq 5$ \\
Personal accomplishment & $\leq 33$ & $34-39$ & $\geq 40$ \\
\hline
\end{tabular}


Table II: Burnout profiles

\begin{tabular}{|c|c|c|c|}
\hline & Emotional exhaustion & Depersonalisation & Personal accomplishment \\
\hline Engaged & low & low & high \\
\hline Ineffective & low to moderate & low to moderate & low \\
\hline Overextended & high & low to moderate & low to moderate \\
\hline Disengaged & low to moderate & high & low to moderate \\
\hline Burnout & high & high & low \\
\hline
\end{tabular}

high exhaustion and depersonalisation scores and low personal accomplishment. Three one-dimension patterns emerge; overextended, where there is only exhaustion, disengagement with only depersonalisation and ineffective with only low personal accomplishment. ${ }^{6}$

\section{Areas of Worklife Survey}

The Areas of Worklife Survey ${ }^{22}$ includes 28 questions relating to the six areas of work-life on which participants indicate the extent to which their experience aligns with their expectations or aspirations for work (Figure 2). All items are rated on a 5-point Likert scale measuring level of agreement. Items are worded as statements of perceived congruence or incongruence between oneself and the job. Items were assigned numerical values in descending order with a level of agreement from 'strongly agree' to 'strongly disagree', 5 to 1 , with high scores $(>3)$ indicating a better degree of congruence, lower scores $(<3)$ indicating greater incongruence between the person and the organisation. For each area, an average is calculated with reverse scoring applied where applicable.

\section{Statistical analysis}

Results are summarised in frequency tables as the number (percentage). Statistica version 13.5.0.17 was used to do statistical analysis. ${ }^{26}$ Differences in the distribution of emotional exhaustion, depersonalisation and personal accomplishment by gender and position were analysed via non-parametric methods using the Spearman's Rank Correlation Coefficient with significance accepted at $p<0.05$.

Data collected via the AWS were treated as non-parametric variables and described as medians, and interquartile ranges to indicate variability. The independent variables were grouped by position with the dependant variables being tested workload, control, reward, community, fairness and values. Hypothesis testing was done using non-parametric methods: Kruskal-Wallis tests were used to determine differences between groups, and differences in distribution were determined by Spearman's Rank Correlation Coefficient. Significance was accepted at $p<0.05$ throughout.

\section{Results}

The survey had a 59\% response rate with 75 members of staff completing the full survey. Characteristics of the respondents are presented in Table III.
Table III: Respondent characteristics $(\boldsymbol{n}=75)$

\begin{tabular}{lc}
\hline & $\boldsymbol{n}(\%)$ \\
\hline Gender & $33(44)$ \\
Male & $42(56)$ \\
Eemale & \\
Full time & $71(95)$ \\
Part time & $4(5)$ \\
Position & \\
Medical officer & $4(5)$ \\
Junior registrar & $15(20)$ \\
Senior registrar & $23(31)$ \\
Junior consultant & $13(17)$ \\
Senior consultant & $20(27)$ \\
\hline
\end{tabular}

On the MBI-HSS, the participants' median score for emotional exhaustion was high [29 (IQR: 22-35)]. For depersonalisation, the participants' median score was moderate [9 (IQR: 5-15)] and the personal accomplishment score was moderate [35 (IQR: 29-39)]. Analysis of the components of burnout by gender revealed that the female respondents were at higher risk of emotional exhaustion with more classified as high and moderate risk (Table IV).

We did not analyse burnout by employment status (full time vs part-time) due to the very small number of respondents $(n=4)$ who were working part-time.

Analysis of the components of burnout by position revealed that for depersonalisation, there were significant differences between positions with registrars appearing particularly vulnerable. In the senior registrars group $(n=23), 66 \%$ were reporting high levels of depersonalisation whilst $60 \%$ of the junior registrars reported high levels of depersonalisation (Table V).

\section{Burnout patterns}

Respondents were classified according to the burnout profile patterns suggested by Leitner and Maslach. According to this classification, three (4\%) of the respondents were classified as burnout. Nine of the respondents were overextended (12\%), nine were ineffective (12\%), two were engaged (3\%), and four of the respondents were classified as disengaged (5\%) (Table Vl). Fortyeight $(64 \%)$ did not meet the criteria for any specific profile. In $50(67 \%)$ of the respondents, high risk for developing clinically significant burnout were seen with high emotional exhaustion and/or depersonalisation. 
Table IV: Distribution of male vs female respondents scoring high, moderate and low for each of the components of burnout $(n=75)$

\begin{tabular}{|c|c|c|c|c|}
\hline & $\begin{array}{c}\text { Emotional exhaustion } \\
\text { High } \\
n(\%) \\
\curvearrowleft\end{array}$ & $\begin{array}{c}\text { Emotional exhaustion } \\
\text { Moderate } \\
n(\%) \\
@\end{array}$ & $\begin{array}{c}\begin{array}{c}\text { Emotion exhaustion } \\
\text { Low } \\
n(\%) \\
\bigodot\end{array}\end{array}$ & Statistical test \\
\hline Female & $29(69)$ & $7(17)$ & $6(14)$ & Spearman \\
\hline Male & $16(49)$ & 13 (39) & $4(12)$ & $\mathrm{R}=0.24 ; p=0.04^{*}$ \\
\hline Female & $22(52)$ & $7(17)$ & $13(31)$ & \multirow{2}{*}{$\begin{array}{c}\text { Spearman } \\
\mathrm{R}=0.075 ; p=0.52\end{array}$} \\
\hline \multirow[t]{2}{*}{ Male } & $14(43)$ & $8(24)$ & $11(33)$ & \\
\hline & $\begin{array}{l}\text { Personal accomplishment } \\
\text { High } \\
n(\%) \\
\bullet\end{array}$ & $\begin{array}{c}\text { Personal accomplishment } \\
\text { Moderate } \\
n(\%) \\
\because\end{array}$ & $\begin{array}{c}\text { Personal accomplishment } \\
\text { Low } \\
n(\%) \\
\curvearrowleft\end{array}$ & \\
\hline Female & $22(52)$ & $13(31)$ & $7(17)$ & \multirow{2}{*}{$\begin{array}{c}\text { Spearman } \\
\mathrm{R}=0.05 ; p=0.67\end{array}$} \\
\hline Male & $11(33)$ & $12(36)$ & $10(30)$ & \\
\hline
\end{tabular}

* indicates significance at $p<0.05$

Emotional exhaustion (EE) and depersonalisation (DP) increases with severity as the score increases in contrast with lack of personal accomplishment (PA) which increases in severity as the score decreases.

Table V: Distribution of respondents by position scoring high, moderate and low for each of the components of burnout ( $n=75$ ).

\begin{tabular}{|c|c|c|c|c|}
\hline & \begin{tabular}{c} 
Emotional exhaustion \\
High \\
$n(\%)$ \\
\hdashline
\end{tabular} & $\begin{array}{c}\text { Emotional exhaustion } \\
\text { Moderate } \\
n(\%) \\
œ\end{array}$ & $\begin{array}{c}\text { Emotional exhaustion } \\
\text { Low } \\
n(\%) \\
\bullet\end{array}$ & Statistical test \\
\hline Total & $45(60)$ & $20(27)$ & $10(13)$ & \multirow{6}{*}{$\begin{array}{c}\text { Spearman } \\
\mathrm{R}=0.18 \\
p=0.13\end{array}$} \\
\hline Medical officer $(n=4)$ & $1(25)$ & $0(0)$ & $3(75)$ & \\
\hline Junior registrar $(n=15)$ & $9(60)$ & $5(33)$ & $1(7)$ & \\
\hline Senior registrar $(n=23)$ & $18(78)$ & $4(18)$ & $1(4)$ & \\
\hline Junior consultant $(n=13)$ & $5(39)$ & $6(46)$ & $2(15)$ & \\
\hline \multirow[t]{2}{*}{ Senior consultant $(n=20)$} & $12(60)$ & $5(25)$ & $3(15)$ & \\
\hline & $\begin{array}{c}\text { Depersonalisation } \\
\text { High } \\
\boldsymbol{n}(\%) \\
\bigodot\end{array}$ & $\begin{array}{c}\text { Depersonalisation } \\
\text { Moderate } \\
n(\%) \\
\because\end{array}$ & $\begin{array}{c}\text { Depersonalisation } \\
\text { Low } \\
n(\%) \\
\bigodot\end{array}$ & \\
\hline Total & $36(48)$ & $15(20)$ & $24(32)$ & \multirow{6}{*}{$\begin{array}{c}\text { Spearman } \\
\mathrm{R}=0.33 \\
p=0.004^{*}\end{array}$} \\
\hline Medical officer $(n=4)$ & $1(25)$ & $1(25)$ & $2(50)$ & \\
\hline Junior registrar $(n=15)$ & $9(60)$ & $2(13)$ & $4(27)$ & \\
\hline Senior registrar $(n=23)$ & $15(66)$ & $4(17)$ & $4(17)$ & \\
\hline Junior consultant $(n=13)$ & $5(38)$ & $5(38)$ & $3(24)$ & \\
\hline \multirow[t]{2}{*}{ Senior consultant $(n=20)$} & $6(30)$ & $3(15)$ & $11(55)$ & \\
\hline & $\begin{array}{l}\text { Personal accomplishment } \\
\text { High } \\
n(\%) \\
\bullet\end{array}$ & $\begin{array}{c}\text { Personal accomplishment } \\
\text { Moderate } \\
n(\%) \\
\because\end{array}$ & $\begin{array}{l}\text { Personal accomplishment } \\
\text { Low } \\
n(\%) \\
\curvearrowleft\end{array}$ & \\
\hline Total & $33(44)$ & $25(33)$ & $17(23)$ & \multirow{6}{*}{$\begin{array}{c}\text { Spearman } \\
\mathrm{R}=0.05 \\
p=0.69\end{array}$} \\
\hline Medical officer $(n=4)$ & $2(50)$ & $1(25)$ & $1(25)$ & \\
\hline Junior registrar $(n=15)$ & $6(40)$ & $5(33)$ & $4(27)$ & \\
\hline Senior registrar $(n=23)$ & $11(48)$ & $8(35)$ & $4(17)$ & \\
\hline Junior consultant $(n=13)$ & $6(46)$ & $4(31)$ & $3(23)$ & \\
\hline Senior consultant $(n=20)$ & $8(40)$ & $7(35)$ & $5(25)$ & \\
\hline
\end{tabular}

*indicates $p<0.05$

Emotional exhaustion and depersonalisation increases with severity as the score increases in contrast with lack of personal accomplishment which increases in severity as the score decreases. 
Table VI: Burnout profile patterns of all respondents and by position

\begin{tabular}{|c|c|c|c|c|c|c|}
\hline & $\begin{array}{c}\text { Engaged } \\
n(\%)\end{array}$ & $\begin{array}{c}\text { Ineffective } \\
n(\%)\end{array}$ & $\begin{array}{l}\text { Overextended } \\
n(\%)\end{array}$ & $\begin{array}{c}\text { Disengaged } \\
n(\%)\end{array}$ & $\begin{array}{c}\text { Burnout } \\
n(\%)\end{array}$ & $\begin{array}{c}\text { Unclassified } \\
n(\%)\end{array}$ \\
\hline $\begin{array}{l}\text { Total } \\
(n=75)\end{array}$ & $2(3)$ & $9(12)$ & $9(12)$ & $4(4)$ & $3(4)$ & $48(64)$ \\
\hline $\begin{array}{l}\text { Medical officer } \\
(n=4)\end{array}$ & $0(0)$ & $1(25)$ & 0 & $1(25)$ & 0 & $2(50)$ \\
\hline $\begin{array}{l}\text { Junior registrar } \\
(n=15)\end{array}$ & 0 & $1(7)$ & $2(13)$ & $2(13)$ & $2(13)$ & $8(53)$ \\
\hline $\begin{array}{l}\text { Senior registrar } \\
(n=23)\end{array}$ & 0 & $2(9)$ & $2(9)$ & $1(4)$ & 1 (4) 19 (82) & $17(74)$ \\
\hline $\begin{array}{l}\text { Junior consultant } \\
(n=13)\end{array}$ & $1(8)$ & $4(31)$ & 0 & 0 & $05(38)$ & $8(62)$ \\
\hline $\begin{array}{l}\text { Senior consultant } \\
(n=20)\end{array}$ & $1(5)$ & $2(10)$ & $5(25)$ & 0 & $012(60)$ & $12(60)$ \\
\hline
\end{tabular}

Table VII: Responses to the areas of work-life survey by position

\begin{tabular}{|c|c|c|c|c|c|c|}
\hline & $\begin{array}{c}\text { Workload } \\
\text { median (IQR) }\end{array}$ & $\begin{array}{c}\text { Control } \\
\text { median (IQR) }\end{array}$ & $\begin{array}{c}\text { Reward } \\
\text { median (IQR) }\end{array}$ & $\begin{array}{l}\text { Community } \\
\text { median (IQR) }\end{array}$ & $\begin{array}{c}\text { Fairness } \\
\text { median (IQR) }\end{array}$ & $\begin{array}{c}\text { Values } \\
\text { median (IQR) }\end{array}$ \\
\hline All positions & $2.2(1.8-2.6)$ & $3(2.3-3.5)$ & $3.3(2.5-4)$ & $3.6(3.2-4)$ & $2.7(2.2-3.3)$ & $3.5(3.3-4)$ \\
\hline $\begin{array}{l}\text { Medical officer } \\
(n=4)\end{array}$ & $2.9(2-3.4)$ & $2.8(2.15-3.4)$ & $3.9(3.15-4)$ & $3.55(3-4.1)$ & $2.73(2.1-3.35)$ & $3.95(3.75-4.15)$ \\
\hline $\begin{array}{l}\text { Junior registrar } \\
(n=15)\end{array}$ & $2.4(2-2.8)$ & $2.8(2.3-3.3)$ & $2.8(2-3.5)$ & $3.2(2.6-4)$ & $3.2(2.3-3.5)$ & $3.5(3.3-4)$ \\
\hline $\begin{array}{l}\text { Senior registrar } \\
(n=23)\end{array}$ & $2.2(1.8-2.4)$ & $2.5(2-2.8)$ & $3.3(2.5-3.8)$ & $3.2(3-3.6)$ & $2.5(2-3.3)$ & $3.5(2.8-4)$ \\
\hline $\begin{array}{l}\text { Junior consultant } \\
(n=13)\end{array}$ & $2(1.6-2.2)$ & $3.3(2.5-3.5)$ & $3.3(2.5-4)$ & $3.6(3.6-4)$ & $2.5(2.5-2.8)$ & $3.3(3-3.8)$ \\
\hline $\begin{array}{l}\text { Senior consultant } \\
(n=20)\end{array}$ & $2.1(1.7-2.4)$ & 3.65 (3.15-4) & $3.4(3-4)$ & $3.7(3.2-4)$ & $2.95(1.75-3.7)$ & $3.8(3.5-4)$ \\
\hline
\end{tabular}

Table VIII: Percentage of participants with high levels of the three dimensions of burnout in different cohorts of anaesthetists ${ }^{18}$

\begin{tabular}{|c|c|c|c|c|c|c|}
\hline & $\begin{array}{c}\text { Groote Schuur (current } \\
\text { study) }\end{array}$ & $\begin{array}{c}\text { Gauteng } \\
\text { RSA }^{18}\end{array}$ & Portugal $^{27}$ & Australia $^{28}$ & USA $^{29}$ & Romania $^{30}$ \\
\hline$\%$ High emotional exhaustion & 60 & 45 & 58 & 20 & 30 & 34 \\
\hline \% High depersonalisation & 48 & 50 & 91 & 20 & 10.5 & 38 \\
\hline \% Low personal accomplishment & 17 & 46 & 45 & 36 & 7 & 38 \\
\hline
\end{tabular}

\section{Areas of Worklife Survey - Organisational risk factors}

Overall, the respondents' perception of appropriateness of workload was poor with a median score of 2.2 (IQR1.8-2.6) (Table VII). However, the responses for the categories of control, reward, community, fairness and values were all in the acceptable range.

Analysis of differences in the perception of workload by position (i.e. junior vs senior doctors) revealed no differences between groups $(p=0.17)$. For the perception of control, there was a significant difference between groups with consultants having a greater sense of control in AWL $(p=0.0001)$. There was no difference by position in the sense of reward $(p=0.24)$, the sense of community $(p=0.06)$, a sense of fairness $(p=0.68)$ or in the values of the organisation $(p=0.13)$.

\section{Association between burnout and organisational risk factors}

Analysis of association between the burnout profile and the individual organisational risk factors of the AWS showed no association between the burnout profile and any of the AWL components.

\section{Discussion}

This study aimed to not only identify the levels of burnout in a cohort of anaesthetists working at Groote Schuur Hospital, but also the possible modifiable organisational risk factors as measured by the AWS, which have previously been associated with burnout.

Although only four percent of respondents were classified as having burnout, markedly lower than any other recent South African study, $67 \%$ scored high for at least one of the components of burnout placing the majority of the respondents at risk of developing clinically significant burnout. A possible protective factor in this cohort was personal accomplishment. The majority of respondents (68\%) reported high to moderate levels of personal accomplishment potentially reducing the overall rate of burnout compared with other studies (Table VIII).

Worrisome in the current study is that $69 \%$ of female respondents scored high for emotional exhaustion compared to only $49 \%$ of male respondents. It appears that females may be especially vulnerable to developing emotional exhaustion, a finding in keeping with the results from a study at Wits University. ${ }^{18}$ The 
increased risk for emotional exhaustion in females has been attributed to multiple factors. These include females being excluded from decision making positions; females' skills being overlooked and not utilised; and family responsibilities falling heavily on women which may make work-life balance especially difficult. ${ }^{31,32}$

Inappropriate workload was the most significant risk factor in the AWS with a median score of 2.2 (IQR 1.8-2.6). Inappropriate workload has been identified as having a strong connection with emotional exhaustion, accounting for the majority of respondents being classified as overextended (12\%), a profile singularly concerned with work demands. ${ }^{6}$

Of concern is that high depersonalisation was observed in the majority of registrars (60-66\%), significantly higher than the consultant group $(30-38 \%, p=0.004)$. This suggests a vulnerability in the social context in which registrars operate as depersonalisation is well correlated with organisational values, emotional and social connections and the overall work environment and teamwork. ${ }^{6}$ In this study the perception of control, as measured by the AWS, over the work environment was significantly lower in the registrar group (2.5-2.8) compared to the consultant group $(3.3-3.65)(p=0.0001)$. The lower perception of control could account for the high levels of depersonalisation among the registrars. This pattern is similar to that reported at Wits University where a trend towards higher overall burnout scores were observed in the registrars compared to the consultants. The vulnerability of registrars or trainees has also been echoed in several other international studies in training institutions. ${ }^{18,33,34}$

\section{Recommendations}

A healthy work environment is essential to promote wellbeing and reduce the risk of burnout. ${ }^{32}$ While individually focused strategies like mindfulness, exercise, meditation, etc., can be encouraged and are known to promote resilience in individuals by strengthening the ability to cope with work demands, organisational strategies have been shown to be far superior in reducing the overall risk of burnout. ${ }^{35}$ Based on the results of this study, two organisational risk factors can be targeted to reduce the risk of burnout. These are workload and the perception of control, particularly among registrars. Numerous strategies which have been found to effectively address these risk factors are summarised in Table IX.

Table IX: Strategies to lessen workload and promote control ${ }^{17}$

\begin{tabular}{|c|c|}
\hline Workload & $\begin{array}{l}\text { Decrease clerical load }{ }^{36-38} \\
\text { Reduction of frustration of clinicians with regards } \\
\text { to equipment, resources and staffing } \\
\text { Locum or contract posts during periods of annual } \\
\text { leave or maternity leave }{ }^{36} \\
\text { Appointing appropriate staff numbers }{ }^{36}\end{array}$ \\
\hline Control & $\begin{array}{l}\text { Autonomy in planning working schedules and } \\
\text { working hours } \\
\text { Allowing clinicians to plan their leave }{ }^{37,40} \\
\text { Use of flexible working hours according to peak } \\
\text { patient load } 37,40,41\end{array}$ \\
\hline
\end{tabular}

\section{Limitations}

There are several limitations to this study. Firstly, the limited sample means the results are not generalisable. However, we believe identifying the particular risk in trainees in this cohort and identifying organisational strategies to mitigate these risks may be transferable to other settings.

It must be noted that due to the sensitive nature of the questionnaire, respondents may have been reluctant to participate in the survey introducing a risk of recruitment bias skewing the results. While the anonymous nature of the survey aimed to reduce this risk, the possibility of reprisal from managerial staff may have been a concern for some.

There still exists great disagreement on the definition of burnout among researchers with many studies using single dimension constructs like emotional exhaustion alone as a proxy to define the burnout syndrome making comparisons difficult if not impossible. ${ }^{42,43}$ We have elected to use all three dimensions in classifying a person as burnout as per the original construct by Leitner and Maslach. Being burnt out is a much more negative experience of the work-life environment than just being emotionally exhausted, furthermore, the disengaged profile (high on depersonalisation only) is also more negative on many important work-life aspects than the overextended profile (high on emotional exhaustion only), pointing to the critical role depersonalisation plays in the syndrome. ${ }^{6}$

\section{Conclusion}

Despite a small percentage of respondents meeting the criteria for burnout in the department surveyed, a significant percentage were at risk of becoming burnt out. A specific overall area of concern identified in the work environment is excessive workload.

The registrar population appear to be particularly at risk of developing burnout with a low perception of control being a possible driving risk factor. Apart from addressing the excessive workload, interventions aiming to improve the social context of the work environment with a focus on autonomy in planning working schedules should be implemented to mitigate risk in this group.

It was gratifying to observe that a strong sense of personal accomplishment still exists in the respondents despite the strains on personal and organisational resources. Indeed, this sense of personal accomplishment may have reduced the incidence of burnout in this cohort.

\section{Conflict of interest}

We declare that no conflict of interest exists in creating this research paper.

\section{Funding sources}

No external sources of funding were utilised for the completion of this research project.

\section{Ethics approval}

Ethical approval was obtained from the University of Cape Town, Faculty of Health Sciences Human Research Ethics Committee 
(REC Ref: 617/2017) with the principles of the Declaration of Helsinki adhered to throughout. ${ }^{24}$

\section{ORCID}

\section{MB Groenewald (16) http://orcid.org/0000-0001-6979-780X J van Nugteren (1) http://orcid.org/0000-0001-5529-3208 R Parker (b) http://orcid.org/0000-0003-4823-2487}

\section{References}

1. Bateman C. Consciously cutting to the bone of SA's surgical/anaesthetic delivery. S Afr Med J. 2016;106(2):132-134. https://doi.org/10.7196/SAMJ.2016. v106i2.10526.

2. Ntusi N. Anaesthesia in South Africa. S Afr Med J. 2018;108(6):455-456. https:// doi.org/10.7196/SAMJ.2018.v108i6.13384.

3. Kaschka WP, Korczak D, Broich K. Burnout: a fashionable diagnosis. Dtsch Arztebl Int. 2011;108(46):781-7. https://doi.org/10.3238/arztebl.2011.0781.

4. Grossman ES. How long does it take a registrar to complete the compulsory research project enabling specialist registration? S Afr Med J. 2019;109(4):254258. https://doi.org/10.7196/SAMJ.2019.v109i4.13377.

5. Tucker P, Byrne A. The tiring anaesthetist. Anaesthesia. 2014;69(1):6-9. https:// doi.org/10.1111/anae.12447.

6. Leiter MP, Maslach C. Latent burnout profiles: A new approach to understanding the burnout experience. Burn Res. 2016;3(4):89-100. https://doi.org/10.1016/j. burn.2016.09.001.

7. Maslach C, Schaufeli WB, Leiter MP. Job burnout. Annu Rev Psychol. 2001;52(1):397-422. https://doi.org/10.1146/annurev.psych.52.1.397.

8. Golkar A, Johansson E, Kasahara M, et al. The influence of work-related chronic stress on the regulation of emotion and on functional connectivity in the brain. PLoS One. 2014;9(9):e104550. https://doi.org/10.1371/journal.pone.0104550.

9. Savic I. Structural changes of the brain in relation to occupational stress. Cereb Cortex 2015 Jun;25(6):1554-64. https://doi.org/10.1093/cercor/bht348.

10. Burke RJ, Greenglass ER. Career orientations and psychological burnout in teachers. Psychol Rep. 1988;63(1):107-16. https://doi.org/10.2466/ pro.1988.63.1.107.

11. Honkonen T, Ahola K, Pertovaara $\mathrm{M}$, et al. The association between burnout and physical illness in the general population-results from the Finnish Health 2000 Study. J Psychosom Res. 2016;61(1):59-66. https://doi.org/10.1016/j. jpsychores.2005.10.002

12. Melamed S, Ugarten U, Shirom A, et al. Chronic burnout, somatic arousal and elevated salivary cortisol levels. J Psychosom Res. 1999;46(6):591-8. https://doi. org/10.1016/S0022-3999(99)00007-0.

13. Shanafelt TD, Boone S, Tan L, et al. Burnout and satisfaction with work-life balance among US physicians relative to the general US population. Arch Intern Med. 2012:172(18):1377-85. https://doi.org/10.1001/archinternmed.2012.3199.

14. Salyers MP, Bonfils KA, Luther $L$, et al. The relationship between professional burnout and quality and safety in healthcare: a meta-analysis. J Gen Intern Med. 2017;32:475-82. https://doi.org/10.1007/s11606-016-3886-9.

15. Stodel JM, Stewart-Smith A. The influence of burnout on skills retention of junior doctors at Red Cross War Memorial Children's Hospital: a case study. S Afr Med J. 2011 Feb;101(2):115-8. https://doi.org/10.7196/SAMJ.4431.

16. Stassen W, Van Nugteren B, Stein C. Burnout among advanced life support paramedics in Johannesburg, South Africa. Emerg Med J. 2013;30(4):331-4. https://doi.org/10.1136/emermed-2011-200920.

17. Liebenberg AR, Coetzee JF, Conradie HH, Coetzee JF. Burnout among rural hospital doctors in the Western Cape: comparison with previous South African studies. African J Prim Heal Care Fam Med. 2018;10(1):1-7. https://doi. org/10.4102/phcfm.v10i1.1568.

18. Van der Walt N, Scribante J, Perrie H. Burnout among anaesthetists in South Africa. S Afr J Anaesth Analg. 2015;21(6):27-30. https://doi.org/10.1080/222011 81.2015.1102798.

19. Hawton K, Clements A, Sakarovitch C, Simkin S, Deeks JJ. Suicide in doctors: a study of risk according to gender, seniority and specialty in medical practitioners in England and Wales, 1979-1995. Journal of Epidemiology \& Community Health. 2001:55:296-300. https://doi.org/10.1136/jech.55.5.296.
20. Gurman GM, Klein M, Weksler N. Professional stress in anesthesiology: a review. J Clin Monit Comput. 2012;26(4):329-35. https://doi.org/10.1007/ s10877-011-9328-7.

21. Nyssen AS, Hansez I, Baele P, Lamy M, De Keyser V. Occupational stress and burnout in anaesthesia. Br J Anaesth. 2003;90(3):333-7. https://doi.org/10.1093/ bja/aeg058.

22. Leiter MP, Maslach C. Areas of worklife manual. 5th ed. Elsevier; 2011.

23. Lasalvia $A$, Bonetto $C$, Bertani $M$, et al. Influence of perceived organisational factors on job burnout: survey of community mental health staff. Br J Psychiatry. 2009;195(6):537-44. https://doi.org/10.1192/bjp.bp.108.060871.

24. General Assembly of the World Medical Association. World Medical Association Declaration of Helsinki: ethical principles for medical research involving human subjects. J Am Coll Dent. 2014:81(3):14-8. Available from: https://pubmed.ncbi. nlm.nih.gov/25951678/.

25. Maslach C, Jackson SE, Leiter M. The Maslach Burnout Inventory: Manual. Maslach Burn Invent. 1996.

26. TIBCO Software Inc. [Internet]. 2018. Available from: http://tibco.com

27. Morais A, Maia P, Azevedo A, Amaral C, Tavares J. Stress and burnout among Portuguese anaesthesiologists. Eur J Anaesthesiol. 2006;23(5):433-9. https://doi. org/10.1017/S0265021505001882.

28. Kluger MT, Townend K, Laidlaw T. Job satisfaction, stress and burnout in Australian specialist anaesthetists. Anaesthesia. 2003;58(4):339-45. https://doi. org/10.1046/j.1365-2044.2003.03085.x

29. Downey RL, Farhat T, Schumann R. Burnout and coping amongst anesthesiologists in a us metropolitan area: a pilot study. J Anesth. 2012;21(4):529-34. Available from: https://pubmed.ncbi.nlm.nih.gov/23327025/.

30. Hagau N, Pop RS. Prevalence of burnout in Romanian anaesthesia and intensive care physicians and associated factors. Jurnalul Român Anestezie Ter intensivă J Rom Anest Ter Int. 2012;192(19):117-24. Available from: http://www.jurnalulanestezie.ro/2012/2/6.pdf

31. Quinn MM, Smith PM. Gender, work, and health. Ann Work Expo Heal 2018;62(4):389-92. https://doi.org/10.1093/annweh/wxy019.

32. Patel RS, Bachu R, Adikey A, Malik M, Shah M. Factors related to physician burnout and its consequences: a review. Behav Sci. 2018;8(11):98. https://doi. org/10.3390/bs8110098.

33. Hyman SA, Michaels DR, Berry JM, et al. Risk of burnout in perioperative clinicians. Anesthesiology. 2011;114(1):194-204. https://doi.org/10.1097/ ALN.0b013e318201ce9a.

34. De Oliveira GS, Chang $R$, Fitzgerald $P C$, et al. The prevalence of burnout and depression and their association with adherence to safety and practice standards. Anesth Analg. 2013;117(1):182-93. https://doi.org/10.1213/ ANE.0b013e3182917da9.

35. West CP, Dyrbye LN, Erwin PJ, Shanafelt TD. Interventions to prevent and reduce physician burnout: a systematic review and meta-analysis. Lancet. 2016;388(10057):2272-81. https://doi.org/10.1016/S0140-6736(16)31279-X.

36. De Villiers M, De Villiers P. Doctors' views of working conditions in rural hospitals in the Western Cape. South African Fam Pract. 2004;46(3):21-6. https://doi.org/10 .1080/20786204.2004.10873056.

37. Spickard A Jr, Gabbe SG, Christensen JF. Mid-career burnout in generalist and specialist physicians. JAMA. 2002;288(12):1447. https://doi.org/10.1001/ jama.288.12.1447.

38. Linzer M, Visser MR, Oort FJ, et al. Predicting and preventing physician burnout: results from the United States and the Netherlands. Am J Med. 2001;111(2):1705. https://doi.org/10.1016/S0002-9343(01)00814-2.

39. Wallace JE, Lemaire JB, Ghali WA. Physician wellness: a missing quality indicator. Lancet. 2009;374(9702):1714-21. https://doi.org/10.1016/ S0140-6736(09)61424-0.

40. Keeton K, Fenner DE, Johnson TRB, Hayward RA. Predictors of physician career satisfaction, work-life balance, and burnout. Obstet Gynecol. 2007;109(4):94955. https://doi.org/10.1097/01.AOG.0000258299.45979.37.

41. Stevenson $A D$, Phillips $C B$, Anderson KJ. Resilience among doctors who work in challenging areas: a qualitative study. Br J Gen Pract. 2011;61(588):e404-10. https://doi.org/10.3399/bjgp11X583182.

42. Eckleberry-Hunt J, Kirkpatrick $H$, Barbera T. The problems with burnout research Acad Med. 2018;93(3):367-70. https://doi.org/10.1097/ACM.0000000000001890.

43. Lee RT, Ashforth BE. A meta-analytic examination of the correlates of the three dimensions of job burnout. J Appl Psychol. 1996;81(2):123-33. https://doi. org/10.1037/0021-9010.81.2.123. 